\title{
The Rheological Characteristics of Dammar Mata Kuching
}

\author{
Chairul Umam ${ }^{1 *}$, Azhar ${ }^{1}$, and Elida Purba ${ }^{1,}$
}

\author{
${ }^{1}$ Departemen of Chemical Engineering, Universitas Lampung, Jalan Prof. Soemantri Brojonegoro No.1, Bandar Lampung \\ 35145, Indonesia \\ *Email:Cumam421@gmail.com
}

\section{Article Information: \\ Received: \\ 14 October 2020 \\ Received in revised form: \\ 14 November 2020 \\ Accepted: \\ 5 December 2020}

Volume 2, Issue 2, December 2020

pp. $97-101$

(C) Universitas Lampung

\begin{abstract}
Rheology is already defined as the science of flow and deformation of matter. The purpose of rheology is to look at the relationships between stress and deformation of the material-material (non-Newtonian) in order to explain its mechanical properties. One of the ingredients that is often used as a basic material for making products is dammar. Dammar is a general term used to name a material in the form of natural resin which is the result of exudation of trees from the Dipterocarpaceae and Burseraccae families. This research used raw materials dammar and toluene which were used to make a solution of dammar with the proportion of dammar: toluene, namely 50: 50, 40: 60, 35: 65, and 30: 70. Then the rheological analysis was analyzed by measuring the viscosity value, the shear rate. , and also its shear stress. The viscosity value increased with the greater the shear rate and the value of $n$ (Flow Behavior index) is $>1$, indicating that a solution of resin was a fluid with a type of dilatant fluid.
\end{abstract}

Keywords: dammar, deformation, rheology, shear rate, shear stress.

\section{INTRODUCTION}

$\mathrm{R}$ heology is already defined as the science of flow and deformation of matter[1-2]. The purpose of rheology is to look at the relationships between stress and deformation of the materialmarterial (non-Newtonian) in order to explain its mechanical properties[3].

The properties and behavior of materials vary from one material to another. Viscosity is one of the physical properties possessed by liquid substances. Viscosity is also a parameter in rheology. Other parameters in rheology are shear stress and shear rate.

The relation between shear rate, shear stress and viscocity we can group the types of flow (Newtonian fluid and non newtonian fluid). The characteristics of fluid type is shown in figure 1.

Newtonian fluid is the fluid whose viscosity not affected by increase or decrease shear rate. Pseudoplastic fluid is the fluid whose viscosity decrease when shear rate is increase. Dilatan Fluid is the fluid whose viscocity is increase when shear rate is also increase.[5]

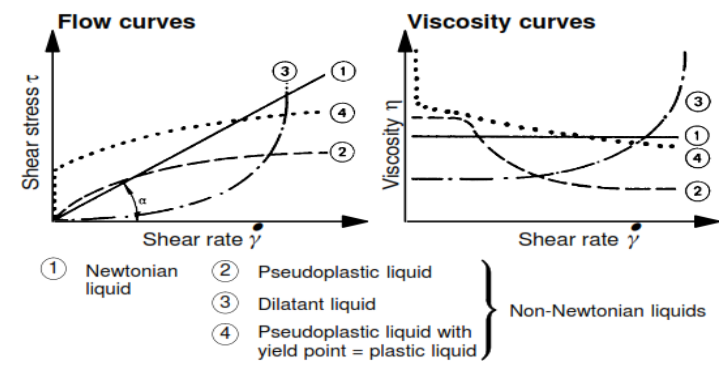

Figure 1.The relationship between shear rate vs shear stress and shear rate vs viscosity $($ scramm, 1998) [4]

By studying rheology, the rheological character of each material can be known and this can be related to processes involving mass transfer, heat and momentum transfer. In the industrial world, rheology is used for the development of a product and also for designing a system used to process a material.

One of the materials that is often used as a base for making products is dammar. Dammar is a general term used to name a material in the form of natural resin which is the result of exudation of trees from the Dipterocarpaceae and Burseraccae families[6]. In terms of its physical and chemical 
properties, resin can be used as an ingredient for industrial products such as paints, waxes, varnishes, plastics, matches, isolative materials, printing materials, asphalt mixtures, and industrial explosives[7-8].

Previous research about Dammar mata kucing is to identify chemical components of Dammar Mata Kuching with the pyrolisis-GC/MS method. The result of that research is Dammar Maata Kuching containing approx 67 compounds, and can be categorized into four group, namely tetracyclic carbon (30 compounds, 49.57\%), pentacyclic (3 compounds, $2.56 \%$ ), compound C (11 compounds, $17.09 \%$ ), and other groups (23 compounds, $18.26 \%)$.[8]

Different from previous research, The purpose of this research is to determine the rheological characteristics of resin. It is important to know the rheological characteristics of resin in order to be able to design or select a device which can handle a process easily and to do so accurately and reproductively.

\section{Materials AND MethodS}

Dammar that we used was a quality dammar mata kuching obtained from West Lampung and the solvent was toluene. There are 4 stages in this research, namely preparation of material, sample making, sample analysis, and data analysis.

1. Preparation of materials

The chunks of dammar were crushed and then sifted to separate the impurities in the form of dammar bark using a 300 micron sieve. Then each weigh 100, 80, 70, 60 grams for each sample.

Weigh the toluen solvent with the respective masses of 100, 120,130, 140 grams.

\section{Sample preparation}

The sifted resin is then dissolved with a solvent in the form of toluene into a beaker with the following design that shows in table 1:

Table 1. Research design

\begin{tabular}{cccc}
\hline No & $\begin{array}{c}\text { Name } \\
\text { of } \\
\text { sample }\end{array}$ & $\begin{array}{c}\text { Wheight } \\
\text { (gram) } \\
\text { Toluen : } \\
\text { Dammar }\end{array}$ & $\begin{array}{c}\text { Percentage } \\
(\%) \\
\text { Toluen : } \\
\text { Dammar }\end{array}$ \\
\hline 1 & LD 1 & $100: 100$ & $50: 50$ \\
2 & LD 2 & $120: 80$ & $60: 40$ \\
3 & LD 3 & $130: 70$ & $65: 35$ \\
4 & LD 4 & $140: 60$ & $70: 30$ \\
\hline
\end{tabular}

3. Sample analisss
Sample analysis was performed to obtain rheological parameter data, namely, viscosity, shear rate and shear stress. The analytical tool used is the HAAKE Viscotester Thermoscience. Performed at a temperature of $30^{\circ} \mathrm{C}$ with a spindle speed of $64.6 ; 107.8 ; 179.6 ; 297.6 \mathrm{rpm}$.

\section{Data analysis}

For viscosity data analysis using the Ostwald-de Waele equation or the Power Law equation.

$$
\sigma=K \cdot \gamma^{n}
$$

$$
\begin{aligned}
\mathrm{K} & =\text { consistency coefficient } \\
\sigma & =\text { shear stress } \\
\dot{\gamma} & =\text { Shear rate } \\
\mathrm{n} & =\text { flow index }=\text { slope log-log flow curve }
\end{aligned}
$$

When the value of $n=1$, the type of fluid is Newtonian and K can also be called viscosity $(\mu)$. If the value $0<n<1$, it is indicated as pseudoplastic fluid. If $n>1$, it is indicated as a dilatant fluid [7].

The power law equation can also describe the apparent viscosity value which is defined as the shear stress divided by the shear rate. following the equation.

$$
\eta=\frac{\sigma}{\dot{\gamma}}=\frac{K \cdot \dot{\gamma}^{n}}{\dot{\gamma}}=K \cdot \dot{\gamma}^{n-1}
$$

\section{RESUlts AND DiscusSiONS}

\section{A. Result}

The following is the measurement results of shear rate, shear stress, and viscosity from a sample of dammar solution:

1. LD 1. Sample of dammar solution (50\% : $50 \%)$

Table 2. Measurement data of resin solution Samples (50\%:50\%)

\begin{tabular}{|l|r|r|r|}
\hline \multicolumn{4}{|c|}{ RUN 1 } \\
\hline Speed 1 & \multicolumn{1}{|c|}{$64,6 / \mathrm{min}$} \\
\hline Time & \multicolumn{1}{|c|}{$60^{\prime}$} & \multicolumn{1}{|c|}{$120^{\prime}$} & $180^{\prime}$ \\
\hline Shear rate $(1 / \mathrm{s})$ & 83,33 & 83,33 & 83,33 \\
Shear stress $(\mathrm{Pa})$ & 0,859 & 0,859 & 0,859 \\
Viscosity $(\mathrm{mPas})$ & 10,3 & 10,3 & 10,3 \\
\hline Speed 2 & $107,8 / \mathrm{min}$ \\
\hline Time & $60^{\prime}$ & $120^{\prime}$ & $180^{\prime}$ \\
\hline Shear rate $(1 / \mathrm{s})$ & 139 & 139 & 139 \\
Shear stress $(\mathrm{Pa})$ & 1,596 & 1,596 & 1,596 \\
Viscosity $(\mathrm{mPas})$ & 11,4 & 11,4 & 11,4 \\
\hline
\end{tabular}




\begin{tabular}{|l|r|r|r|}
\cline { 2 - 4 } Speed 3 & \multicolumn{3}{|c|}{$179,6 / \mathrm{min}^{\prime}$} \\
\hline Time & \multicolumn{1}{|c|}{$60^{\prime}$} & \multicolumn{1}{|c|}{$120^{\prime}$} & \multicolumn{1}{c|}{$180^{\prime}$} \\
\hline Shear rate $(1 / \mathrm{s})$ & 231,6 & 231,6 & 231,6 \\
Shear stress $(\mathrm{Pa})$ & 3,08 & 3,08 & 3,08 \\
Viscosity $(\mathrm{mPas})$ & 12,9 & 12,9 & 12,9 \\
\hline Speed 4 & \multicolumn{3}{|c|}{$297,6 / \mathrm{min}$} \\
\hline Time & \multicolumn{1}{|c|}{$60^{\prime}$} & \multicolumn{1}{|c|}{$120^{\prime}$} & \multicolumn{1}{|c|}{$180^{\prime}$} \\
\hline Shear rate $(1 / \mathrm{s})$ & 383,9 & 383,9 & 383,9 \\
Shear stress $(\mathrm{Pa})$ & 5,464 & 5,464 & 5,464 \\
Viscosity $(\mathrm{mPas})$ & 14,2 & 14,2 & 14,2 \\
\hline
\end{tabular}

2. LD 2. Sample of dammar solution $(60 \%$ : $40 \%)$

Table 3. Measurement data of resin solution Samples $(60 \%: 40 \%)$

\begin{tabular}{|l|l|l|l|}
\hline \multicolumn{4}{|l|}{ RUN 2} \\
\hline Speed 1 & $64,6 / \mathrm{min}$ \\
\hline Time & $60^{\prime}$ & $120^{\prime}$ & $180^{\prime}$ \\
\hline Shear rate $(1 / \mathrm{s})$ & 83,33 & 83,33 & 83,33 \\
Shear stress $(\mathrm{Pa})$ & 0,307 & 0,307 & 0,307 \\
Viscosity $(\mathrm{mPas})$ & 3,68 & 3,68 & 3,68 \\
\hline Speed 2 & $107,8 / \mathrm{min}$ \\
\hline Time & $60^{\prime}$ & $120^{\prime}$ & $180^{\prime}$ \\
\hline Shear rate $(1 / \mathrm{s})$ & 139 & 139 & 139 \\
Shear stress $(\mathrm{Pa})$ & 0,675 & 0,675 & 0,675 \\
Viscosity $(\mathrm{mPas})$ & 4,85 & 4,85 & 4,85 \\
\hline Speed 3 & $179,6 / \mathrm{min}$ \\
\hline Time & $60^{\prime}$ & $120^{\prime}$ & $180^{\prime}$ \\
\hline Shear rate $(1 / \mathrm{s})$ & 231,6 & 231,6 & 231,6 \\
Shear stress $(\mathrm{Pa})$ & 1,412 & 1,412 & 1,412 \\
Viscosity $(\mathrm{mPas})$ & 6,09 & 6,09 & 6,09 \\
\hline Speed 4 & $297,6 / \mathrm{min}^{\prime}$ \\
\hline Time & $60^{\prime}$ & $120^{\prime}$ & $180^{\prime}$ \\
\hline Shear rate $(1 / \mathrm{s})$ & 383,9 & 383,9 & 383,9 \\
Shear stress $(\mathrm{Pa})$ & 2,701 & 2,701 & 2,701 \\
Viscosity $(\mathrm{mPas})$ & 7,03 & 7,03 & 7,03 \\
\hline
\end{tabular}

3. LD 3. Sample of dammar solution $(65 \%$ : $35 \%)$

Table 4. Measurement data of resin solution Samples (65\%: $35 \%)$

\begin{tabular}{|l|r|r|r|}
\hline \multicolumn{4}{|c|}{ RUN 3 } \\
\hline Speed 1 & \multicolumn{1}{|c|}{$64,6 / \mathrm{min}$} \\
\hline Time & \multicolumn{1}{|c|}{$60^{\prime}$} & \multicolumn{1}{|c|}{$120^{\prime}$} & \multicolumn{1}{|c|}{$180^{\prime}$} \\
\hline Shear rate $(1 / \mathrm{s})$ & 83,33 & 83,33 & 83,33 \\
Shear stress $(\mathrm{Pa})$ & 0,245 & 0,245 & 0,245 \\
Viscosity $(\mathrm{mPas})$ & 2,94 & 2,94 & 2,94 \\
\hline Speed 2 & $107,8 / \mathrm{min}$ \\
\hline Time & $60^{\prime}$ & $120^{\prime}$ & $180^{\prime}$ \\
\hline Shear rate $(1 / \mathrm{s})$ & 139 & 139 & 139 \\
Shear stress $(\mathrm{Pa})$ & 0,491 & 0,491 & 0,491 \\
Viscosity $(\mathrm{mPas})$ & 3,53 & 3,53 & 3,53 \\
\hline Speed 3 & $179,6 / \mathrm{min}$ \\
\hline Time & $60^{\prime}$ & $120^{\prime}$ & $180^{\prime}$ \\
\hline Shear rate $(1 / \mathrm{s})$ & 231,6 & 231,6 & 231,6 \\
Shear stress $(\mathrm{Pa})$ & 0,921 & 0,921 & 0,921 \\
Viscosity $(\mathrm{mPas})$ & 3,97 & 3,97 & 3,97 \\
\hline Speed 4 & $297,6 / \mathrm{min}$ \\
\hline Time & $60^{\prime}$ & $120^{\prime}$ & $180^{\prime}$ \\
\hline Shear rate $(1 / \mathrm{s})$ & 383,9 & 383,9 & 383,9 \\
Shear stress $(\mathrm{Pa})$ & 2,333 & 2,333 & 2,333 \\
Viscosity $(\mathrm{mPas})$ & 6,07 & 6,07 & 6,07 \\
\hline
\end{tabular}

4. LD 4. Sample of dammar solution $(70 \%: 30 \%)$

Table 5. Measurement data of resin solution Samples(70\%:30\%)

\begin{tabular}{|c|c|c|c|}
\hline \multicolumn{4}{|c|}{ RUN 4} \\
\hline Speed 1 & \multicolumn{3}{|c|}{$64,6 / \mathrm{min}$} \\
\hline Time & $60^{\prime}$ & $120^{\prime}$ & $180^{\prime}$ \\
\hline Shear rate $(1 / \mathrm{s})$ & 83,33 & 83,33 & 83,33 \\
\hline Shear stress $(\mathrm{Pa})$ & $-1,224$ & $-1,224$ & $-1,224$ \\
\hline Viscosity (mPas) & 0 & 0 & 0 \\
\hline Speed 2 & \multicolumn{3}{|c|}{$107,8 / \mathrm{min}$} \\
\hline Time & $60^{\prime}$ & $120^{\prime}$ & $180^{\prime}$ \\
\hline Shear rate $(1 / \mathrm{s})$ & 139 & 139 & 139 \\
\hline Shear stress $(\mathrm{Pa})$ & 0,061 & 0,061 & 0,061 \\
\hline Viscosity (mPas) & 0,44 & 0,44 & 0,44 \\
\hline Speed 3 & \multicolumn{3}{|c|}{$179,6 / \mathrm{min}$} \\
\hline Time & $60^{\prime}$ & $120^{\prime}$ & $180^{\prime}$ \\
\hline Shear rate $(1 / \mathrm{s})$ & 231,6 & 231,6 & 231,6 \\
\hline Shear stress $(\mathrm{Pa})$ & 0,552 & 0,552 & 0,552 \\
\hline Viscosity (mPas) & 2,38 & 2,38 & 2,38 \\
\hline Speed 4 & \multicolumn{3}{|c|}{$297,6 / \mathrm{min}$} \\
\hline Time & $60^{\prime}$ & $120^{\prime}$ & $180^{\prime}$ \\
\hline Shear rate $(1 / \mathrm{s})$ & 383,9 & 383,9 & 383,9 \\
\hline
\end{tabular}




\begin{tabular}{|l|r|r|r|} 
Shear stress $(\mathrm{Pa})$ & 1,178 & 1,178 & 1,178 \\
Viscosity (mPas) & 4,31 & 4,31 & 4,31 \\
\hline
\end{tabular}

\section{B. Discussion}

To determine the type of dammar solution, it is necessary to know the relationship between shear rate, shear stress, and viscosity. It is the relationship between this three that will determine what type of resin solution is.

In this research, the shear rate value was controlled by adjusting the spindle speed. Data generated and can be seen in measuring instruments, namely shear rate, shear stress and viscosity. The data obtained is then graphed on the relationship between shear rate vs shear stress (figure 2) and shear rate vs viscosity (figure 3 ) as follows.

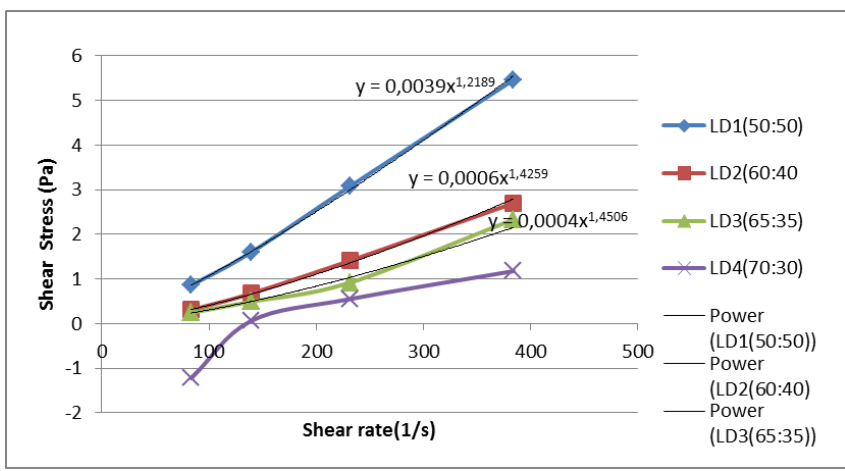

Figure 2.The relationship between shear rate (1/s) vs shear stress (Pa)

From Figure 1 it can be seen, the shear stress value of each sample increases with enlarged shear rate. Shear stress are increase with enlarged shear rate is because the particle in dammar solution is rub again each other which resist the flow.

From the data plotted onto the shear rate vs shear stress graph, the graph equation using the power law model is obtained. The graphical equation for each sample is:

$$
\begin{aligned}
& y=0,0039 x^{1,2189} \\
& y=0,0006 x^{1,4259} \\
& y=0,0004 x^{1,4506}
\end{aligned}
$$

Equation 3 for sample LD1 (50\%: 50\%), equation 4 for sample LD2, equation 5 for sample LD3 (65\%: 35\%).

For the LD4 sample (70\%: $30 \%)$ an equation cannot be made using the power law model because the shear stress value at speed 1 is -1.224 $\mathrm{Pa}$. This negative value of shear stress can be ascertained as the error value generated by the viscosity analyzer. So that to determine the equation for the power law model, start from the second point and get the graphical equation shown by equation 6 .

$$
y=4 E-08 x^{2,9167}
$$

From the graph equation of each sample shows that the value of $\mathrm{n}$ (flow behavior index) for each sample has a value of $n>1$ so the type of fluid from the dammar solution is dilatant fluid.

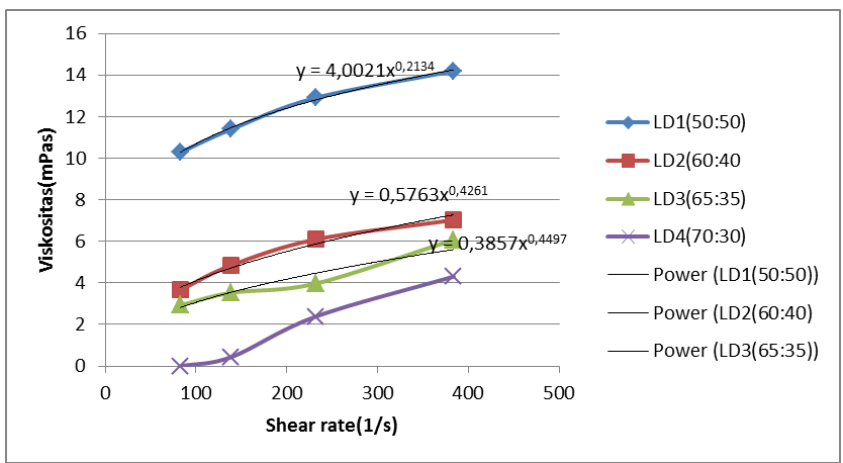

Figure 3.The relationship between shear rate (1/s) vs viscosity (Pas)

The viscosity value increases as the shear rate increases. This indicates that the resin solution is a fluid with a type of dilatant fluid whose viscosity increases when the shear rate is increased.

From the data plotted onto the shear rate vs viscosity graph, the graph equation using the power model is obtained. The graphical equation for each sample is:

$$
\begin{aligned}
& y=4,0021 x^{0,2134} \\
& y=0,5763 x^{0,4261} \\
& y=0,3857 x^{0,4497}
\end{aligned}
$$

Equation 7 for sample LD1 (50\%: 50\%), equation 8 for sample LD2, equation 9 for sample LD3 (65\%: 35\%).

For the LD4 sample (70\%: 30\%) an equation cannot be made using the power law model because the viscosity value at speed 1 is $0 \mathrm{mPas}$. This value of 0 can be ascertained as the error value generated by the viscosity analyzer. So that to determine the equation for the power law model, start from the second point and get the graphical equation shown by equation 10 .

$$
y=8 \mathrm{E}-06 \mathrm{x}^{2,248}
$$

When viewed from the equation on the graph using the power law model, the value of $n$ (flow behavior index) can also be calculated. Where the $n$ value of each sample is $n>1$ which also confirm that dammar solution is a type of dilatant fluid. 


\section{CONCLUSIONS}

When the shear rate is increased, the viscosity and shear stress values increase. So that it can be ascertained that all samples of the resin solution are the same type of fluid, namely the dilatant fluid.

\section{REFERENCES}

[1] A. B. Howard, A Handbook of Elementary Rheology, Wales: The University of Wales Institute of Non-Newtonian Fluid Mechanics, 2000.

[2] M. Hiroshi, Rheology - Theory and Application to Biomaterials, Nagasaki: Nagasaki University, 2012.

[3] V. J. De, Rheologi, Croatia: InTech, 2012.

[4] G. Schramm, A Practical Approach to Rheologyand Rheometry, USA:Haake Instrument Inc, 1998.
[5] B. P.K., K. Godiwalla, D. Sanyal and S. Dev, A simple technique for measurement of apparent viscosity of slurries: san-water system, India: National Metallurgical Laboratory, 2001.

[6] L. Fintia, Pemurnian Beberapa kualitas damar mata kucing (Shorea javanica) dengan sistem pemanasan, Bogor: Institut Pertanian Bogor, 2007.

[7] G. Wiwit, " Damar dalam industri cat," Jurnal riset teknologi, vol. 2, 2008.

[8] Mulyono and Norwayati, Identifikasi Komponen Kimia Damar Mata Kucing (Shorea Javanica) dengan Metode Pirolisis- GC/MS, Bogir: Kampus IPB Darmaga, 2011. 